\title{
Causes of Duodeno-Gastric Reflux as a Surgical Problem
}

Martynov Vladimir Leonidovich

Doctor of Medical Sciences, Associate Professor, National Research Nizhny Novgorod State University, Russia.

Corresponding Author: Martynov Vladimir Leonidovich, Doctor of Medical Sciences, Associate Professor, National Research Nizhny Novgorod State University, Russia.

\section{Received Date: April 28, 2021; Accepted Date: September 10 2021; Published Date: September 232021}

Citation: Martynov Vladimir Leonidovich (2021) Causes of Duodeno-Gastric Reflux as a Surgical Problem. J, Gastroenterology Pancreatology and Hepatobilary Disorders. 5(6); DOI: 10.31579/2641-5194/048

Copyright: (C) 2021, Martynov Vladimir Leonidovich, This is an open access article distributed under the Creative Commons Attribution License, which permits unrestricted use, distribution, and reproduction in any medium, provided the original work is properly cited.

\section{Abstract \\ The author points to duodeno-gastric reflux as gastric precancer. In the overwhelming majority of patients, GHD is caused by compression of the lower-horizontal part of the duodenum by the superior mesenteric artery. \\ Key words: prevention of stomach cancer; duodeno-gastric reflux; chronic violation of duodenal patency; indications for surgery}

\section{Introduction}

The duodenum (12-PC), located in a kind of vascular fork (Figure 1) formed by the superior mesenteric artery (SMA) and the aorta, under certain conditions can be compressed by the SMA or one of its branches, causing arterio-mesenteric compression (AMC) bottom horizontal part 12-PC. which leads to the development of a mechanical form of chronic disorders of duodenal patency (CPD), duodeno-gastric reflux (GDR), which is assumed to be a precancerous state.

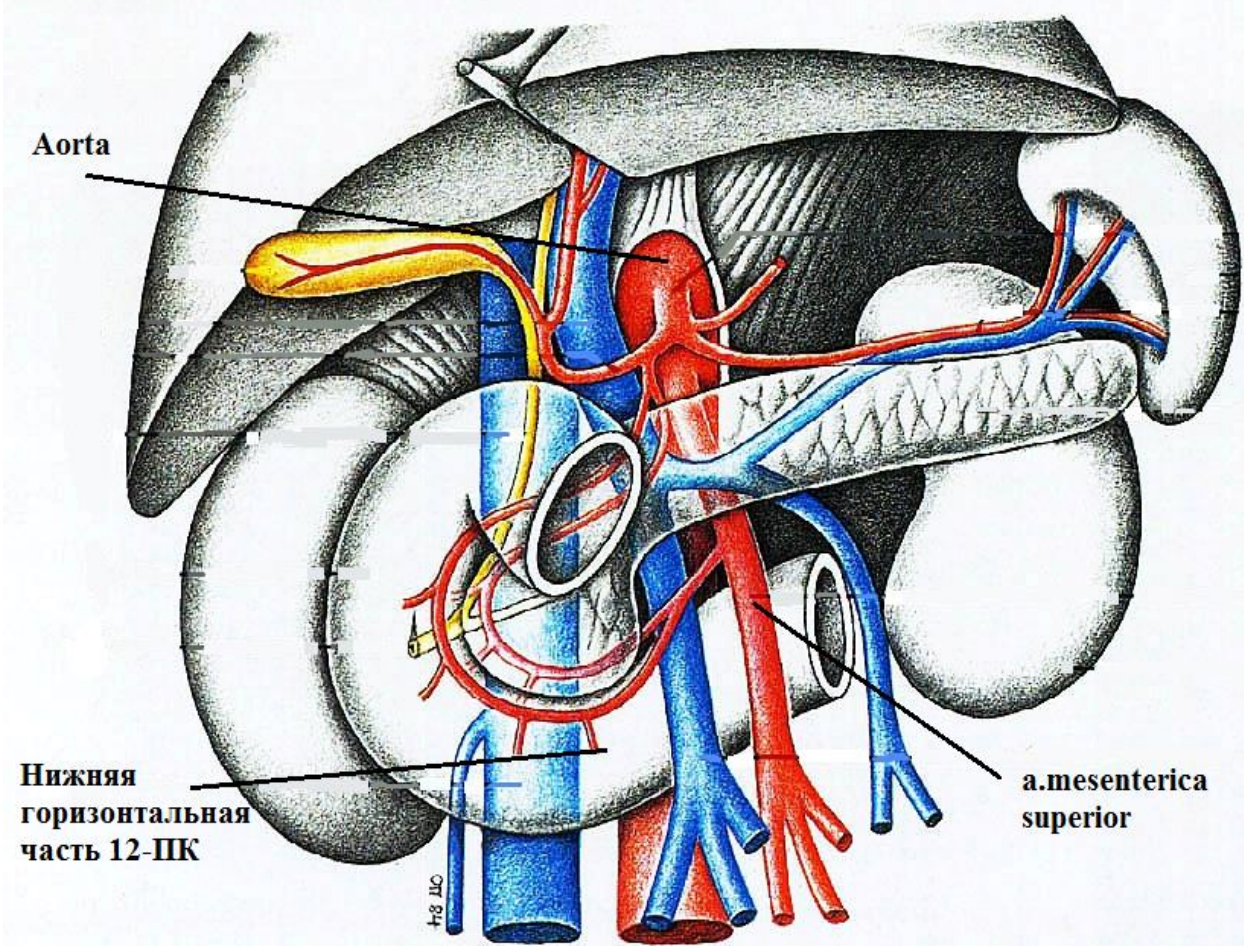


The main pathogenetic factors in the development of stomach diseases in chronic disorders of duodenal patency (CPD) are duodenogastric reflux (DGR) and motor-evacuation disorders of the stomach [1]. Many authors consider GHR as a factor in the formation of chronic gastritis [3], gastric ulcer and 12 duodenal ulcer [1], and stomach cancer [1, 2, 3, 4]. Duodenal hypertension, due to both mechanical and functional reasons, plays a leading role in the occurrence of GHD in patients with chronic cerebrovascular disease $[1,2]$. Damage to the gastric mucosa by the thrown duodenal contents, which includes bile acids and lysolecithin, is considered the main cause of gastric ulceration and cancer [1, 2, 3, 4]. This opinion is confirmed experimentally and by clinical observations. Recognizing the presence of HNDP and the need for its correction with therapeutic measures or surgery, the indications for correction methods, indications for each individual patient are not defined. In the experiment, we tried to find out the degree of arteriomesenteric compression (AMC), when there is a violation of patency in the duodenum. Creation of a model of various degrees of arteriomesenteric compression of the lowerhorizontal part of the duodenum with the determination of the passive flow rate of the experimental fluid. To reveal the role of the AMK degree for passive flow through the small intestine of a human corpse, we have created a model of AMK as one of the forms of HNDP in the pathological hall. The system of the AMK model is as follows (Figure 2): on two screws (1), two strips (3) are fixed with nuts (2). When moving the nuts (2) along the axis of the screw (1), the upper bar also moves, which changes the distance between the bars. The distance between the slats mimics the distance between the aorta and the VMA, i.e. AMK degree. A section of the small intestine with a diameter of $2.5 \mathrm{~cm}$ and a length of $35-40 \mathrm{~cm}$ was placed between the slats (4). The proximal end of the intestine was put on a $2.5 \mathrm{~cm}$ neck of a cut-bottom plastic bottle. The neck of the bottle was fixed at a height of $10 \mathrm{~cm}$ from the slats on a tripod. A constant volume $(500 \mathrm{ml})$ of liquid with a certain viscosity (machine oil) was poured into the bottle.

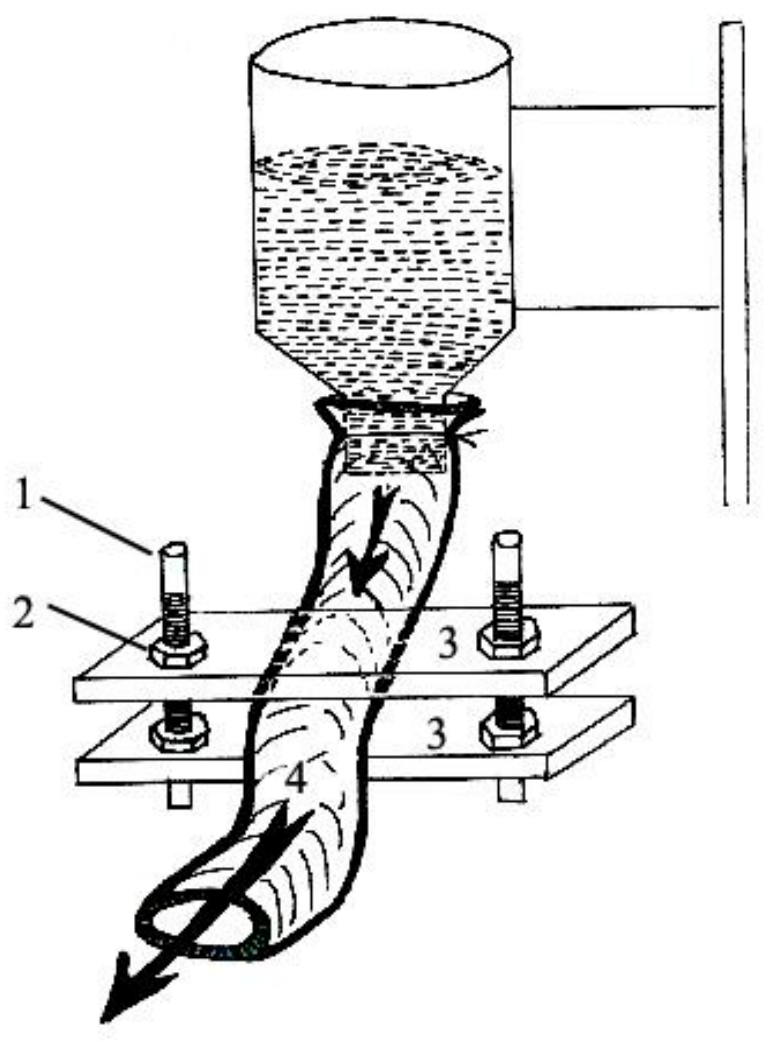

Figure: 2. Model of various degrees of intestinal AMC with the determination of the passive flow rate of the experimental fluid (explanation in the text).

Experience 1. Determined the distance between the bars, equal to the diameter of the neck of the bottle $-2.5 \mathrm{~cm}$. $500 \mathrm{ml}$ of the experimental liquid passed through the intestine in 5.5 seconds, which was taken as $100 \%$.

Experiment 2. Determined the distance between the bars (AMC degree) of $2 \mathrm{~cm}$. The experimental liquid $(500 \mathrm{ml})$ passed through the intestine also in 5.5 seconds ( $100 \%$ of the initial time).

Experiment 3. Determined the distance between the bars (degree of AMK) of $1.5 \mathrm{~cm}$. The experimental liquid $(500 \mathrm{ml})$ passed through the intestine in 7.5 seconds ( $140 \%$ of the initial time).

Experience 4. Determined the distance between the bars (AMC degree) in $1.0 \mathrm{~cm}$. The experimental liquid $(500 \mathrm{ml})$ passed through the intestine in 9 seconds $(170 \%$ of the original time).
Experiment 5. Determined the distance between the strips of $0.5 \mathrm{~cm}$. The experimental liquid $(500 \mathrm{ml})$ passed through the intestine in 28.7 seconds (420\% of the original time).

Determination of the distance between the aorta and the superior mesenteric artery at the level of the lower horizontal part of the duodenum in patients with reflux disease.

Signs of colonic, duodeno-gastric, gastroesophageal reflux were observed in each patient in $94 \%$ of patients. Therefore, in the concept of reflux disease, we combine simultaneously reflux of all three levels.

When determining the specified distance, 129 patients received following results:

$\mathrm{AMC}=5 \mathrm{~mm}-$ in $17(13 \%)$ patients; 
$\mathrm{AMC}=6-10 \mathrm{~mm}-$ in $47(36 \%)$ patients

$\mathrm{AMC}=11-15 \mathrm{~mm}-$ in $31(24 \%)$ patients;

$\mathrm{AMC}=16-20 \mathrm{~mm}-$ in $26(20 \%)$ patients;

$\mathrm{AMC}=21-25 \mathrm{~mm}-$ in $4(3.5 \%)$ patients;
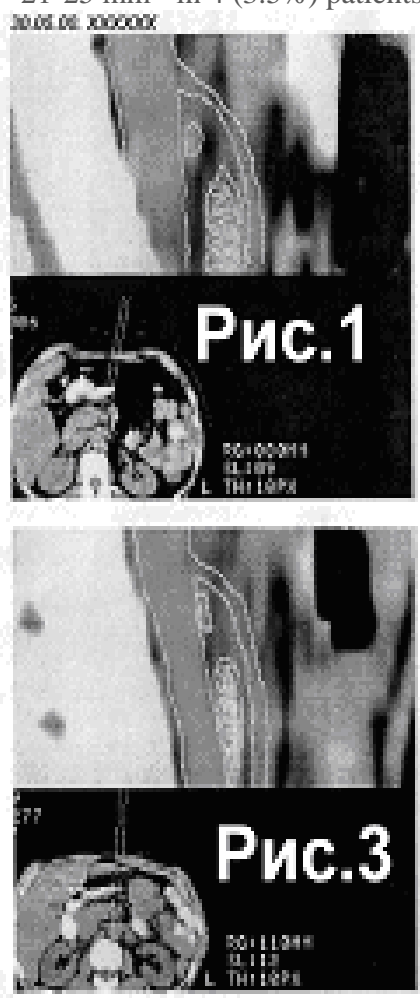

$\mathrm{AMC}>25 \mathrm{~mm}-$ in $4(3.5 \%)$ patients.

Various degrees of compression of the lower-horizontal part of the $12 \mathrm{PC}$ between the aorta and the superior mesenteric artery are shown on computed tomographic images after computed tomography (Figure 3).
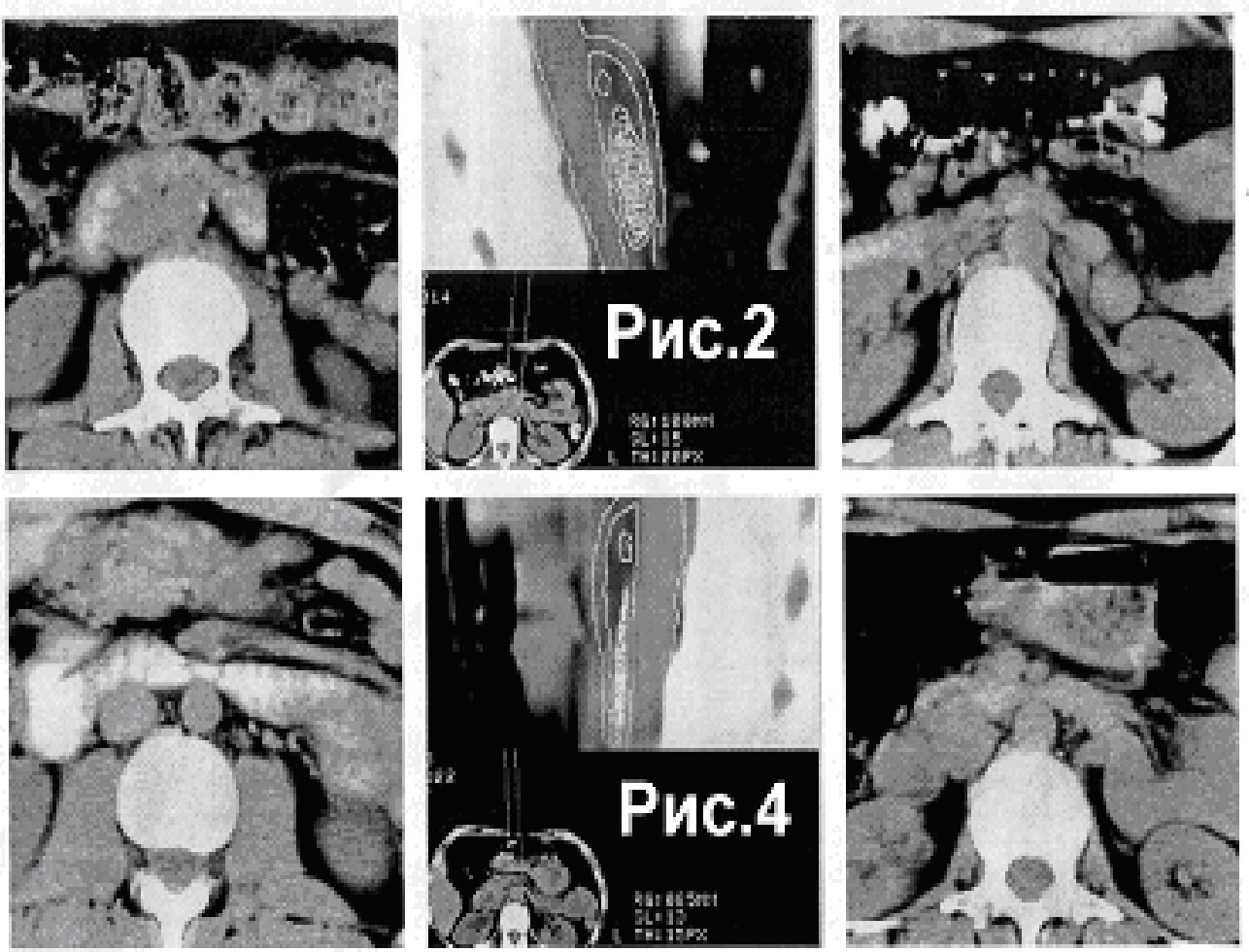

Figure: 3. The computed tomogram shows the degree of compression of the lower-horizontal part of the 12 PC, depending on the distance between the aorta and the superior mesenteric artery.

On CT scans, an increase in the degree of compression is clearly visible in the form of a decrease in the lumen of the lower-horizontal part of the 12th PC between the aorta and the MCA as the distance between these vessels decreases.

\section{Conclusions}

1. When the intestine with a diameter of $2.5 \mathrm{~cm}$ is compressed by $0.5 \mathrm{~cm}$ (by $20 \%$ of the initial diameter), a violation of the passive passage of the experimental fluid through it begins, namely, an increase in the passage time, which increases more than 4 times with external compression of the intestine $80 \%$ of its original diameter.

2. AMC less than $20 \mathrm{~mm}$ (less than the diameter of the duodenum 12) was noted in $121(96.5 \%)$ of 129 patients with reflux disease, which indicates the presence of one of the causes of chronic violation of duodenal patency - compression of the lowerhorizontal part of the duodenum of the upper mesenteric artery, which causes duodeno-gastric reflux, which is one of the causes of stomach cancer according to Virchow's theory of permanent pathological irritation.
3. Surgical correction of GDR in a significant number of patients is a surgical problem.

\section{Reference}

1. V. Martynov, (2014) Refluxes in gastroenterology. Causes, effects, surgical treatment, prospects. Palmarium Academic Publishing. 505 s. ISBN: 978-3-639-70945-2.

2. V. Martynov, (2016) SIBR: surgical treatment and prevention. Palmarium Academic Publishing. 207 s. ISBN: 978-3-659-723544.

3. V. Martynov, D. Kolchin, V. Kurilov. (2018) Surgical prevention of reflux of the digestive system (results and scientific and practical prospects). Palmarium Academic Publishing. 334 p. ISBN: 978620-2-38138-3

4. V.L. Martynov (2020) Prevention of the development of refluxes of the digestive system. Small intestine plug in intraoperative prevention of digestive system reflux development. Palmarium Academic Publishing. 141 p. ISBN: 978-620-2-39416-1. 
This work is licensed under Creative Commons Attribution 4.0 License

To Submit Your Article Click Here: Submit Manuscript

DOI: $10.31579 / 2641-5194 / 048$
Ready to submit your research? Choose Auctores and benefit from:

$>$ fast, convenient online submission

$>$ rigorous peer review by experienced research in your field

$>$ rapid publication on acceptance

$>$ authors retain copyrights

$>$ unique DOI for all articles

$>$ immediate, unrestricted online access

At Auctores, research is always in progress.

Learn more auctoresonline.org/journals/gastroenterology-pancreatologyand-hepatobilary-disorders 